\title{
Key Management Practices within the South African Department of Labour and SETAS
}

\author{
Prof. Theuns Pelser \\ North-West University \\ E-mail: theuns.pelser@nwu.ac.za \\ Johan Kriegler \\ University of the Free State \\ E-mail: johankriegler.com \\ Prof. Hein Prinsloo \\ North-West University \\ E-mail: hein.prinsloo@nwu.ac.za
}

\section{Doi:10.5901/mjss.2014.v5n1p303}

\section{Abstract}

An effective public sector is a crucial role-player to ensure that the development of all sectors of a country is efficient and sustainable. This is especially true for a developing country such as South Africa that needs to address macro socio-economic challenges such as poverty and unemployment. The Senior Management Staff (SMS) in the public sector have a pivotal role to ensure that the public sector is managed effectively. The reason for this qualitative study was to identify the standards that key management practices should comply with, to benchmark the applied practices of the Department of Labour (DoL) and Sectoral Education and Training Authorities (SETAS) against these standards and to recommend guidelines of how these practices could be improved. In addition the improvement of management practices would advance the implementation of strategies and policies and service delivery in the public sector. The guidelines proposed, based on the identified weaknesses should also improve the degree of compliance of the management practices. The improvement in compliance should thus ensure a more effective public sector, which delivers a better service to all citizens and contribute effectively to the sustainable socio-economic growth and development in South Africa.

Keywords: corporate governance; management practices; performance management; performance agreement; performance management and development cycle.

\section{Introduction}

Management is the pivotal force within any organisation and has a major impact on its effectiveness, efficiency and growth. Management refers to practices that are applied by managers during the planning, implementation, monitoring, reporting, assessment and development phases. Management is instrumental in leading, organizing and coordinating resources during these phases to ensure the organisation achieves it goals. The key objective of management should be to satisfy and support the needs of clients, stakeholders, society and the environment in an effective and sustainable manner. To ensure long-term organizational effectiveness, it is therefore important to analyse and improve management practices continuously.

The Constitution of the Republic of South Africa, 1996 (Act 108 of 1996), hereafter referred to as the Constitution, requires the public sector to provide an effective, transparent, accountable and coherent government for the country (Acts, 1996, online). The King Report (2002, p. 15) on Corporate Governance (CG) also indicates that management practices in the public and private sectors must comply with the principles of fairness, accountability, responsibility and transparency. "Management practices" refer to the act or manner of managing that tends to become a habitual or customary performance in a specific working environment (Online Dictionary, 2013, online). The Constitution is the supreme law in South Africa and compliance to the principles of CG is a key criterion to ensure sustainable growth and development in any society (Adam, 2005, p. 15). According to Gordon (2007 p. 21) the key to the economic success of South Africa is the quality of its managers, and this should be the number one national priority. 


\section{Background}

Public managers and more specifically the Senior Management Staff (SMS), which cover the job levels from Director to Director General, are the key management levels who are accountable to deliver a public service that is effective, fair, transparent and coherent (King Report, 2002, p. 12). This type of public service requires management practices to comply with Constitutional and CG principles. These practices are mainly executed during the four phases of the Performance Management and Development (PM\&D) cycle: Planning, monitoring and reporting, review and assessment and management development (Van der Waldt, 2005, p. 52; Bovaird \& Loffler, 2004, p. 132; Mullins, 2002, p. 124). The reason for this study is thus to identify the standards that key management practices should comply with, to benchmark the applied practices of the Department of Labour (DoL) and Sectoral Education and Training Authorities (SETAS) against these standards and to recommend guidelines of how these practices could be improved. In addition the improvement of management practices would improve the implementation of strategies and policies and service delivery in the public sector.)

The SMS are accountable to act in a fair, responsible, transparent and coherent manner. Compliance to these principles is mandated by appropriate legislation, regulations and policies, which stipulate specific standards that the SMS should adhere to. The flow of information and integration between the planning, monitoring and reporting and the review and assessment phases are illustrated in Figure 1.

Figure 1. Integrated planning, monitoring \& reporting and assessment
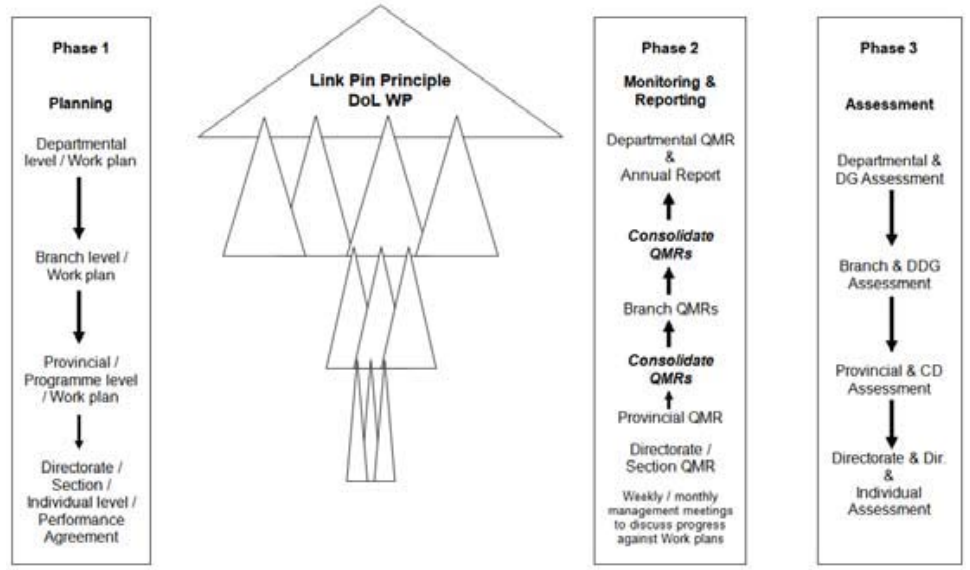

The first step during the planning phase is strategic planning, which provides the basis for formulation of goals and the allocation of resources, including the finalisation of the required budget (Mullins, 2002, p. 125). Strategic planning starts with the SMS drafting strategic and key operational goals for a department (Van der Waldt, 2005, p. 48). These goals should be aligned to national strategic focus areas and respective performance indicators, as agreed by Cabinet. The State of the Nation Address of the President has also introduced a new era for accountability of the SMS in the government. For the first time in the history of South Africa, the head of state gives clear deliverables to government, with specific goals and timeframes (Gordon, 2004, p. 5). These goals are based on strategic discussions and debates within Cabinet and are strongly influenced by the South African public. This process is an illustration of the Batho Pele principles and process, during which the expectations of stakeholders are sought and defined as measurable goals that are communicated to the nation.

An important output of monitoring should be the continuous feedback and discussions of results between managers and their staff (second step). The feedback could be formal such as discussions during monthly performance meetings or informal, when feedback is given on a one-on-one basis. Continuous, specific and balanced performance feedback is one of the most important, but also most neglected accountabilities of managers (Blanchard 2004a, p. 46), as it should be the basis for fair and valid formal assessments which should be conducted bi-annually. The PFMA, Section 4 prescribes that the SMS should report regularly and accurately, against the budget and agreed strategic goals. 
The reports should clearly indicate the results achieved against the strategic and operational goals that were formulated and agreed to during the planning phase. The SMS should also ensure that the Annual Reports are completed accurately and submitted timeously to the Auditor General for his audit comments. Thereafter it should reach the Cabinet timeously, where the results and audit comments are discussed (Public Service Commission, 2007a, p. 42). The King Report (2002, p. 147) also indicated that the SMS must ensure that these reports contain relevant and accurate information and are published and tabled timeously for discussion.

The process of management involves a continuous judgment on the behaviour and performance results of staff. This is done through the review and assessment of the performance and potential of staff. It is important that the SMS and staff know exactly what is expected of them and the goals against which their performance and results will be measured. A formalized and systematic assessment scheme will enable a regular assessment of the performance of the individual, highlighting potential and identifying training and development needs. More important, such an assessment scheme could improve the future performance of staff. Formal review and assessment discussions also form the basis of the extent of performance bonuses and potential career progressions (Van der Waldt, 2005, p. 38). Performance assessment and appraisal (step three) is therefore an important phase during the PM\&D cycle. A comprehensive and effective appraisal system can provide the basis for key management decisions such as those relating to the allocation of duties and responsibilities, pay delegation, levels of supervision, promotions, training and development needs and terminations. According to the Public Service Regulations the SMS shall on a continuous basis give the employee feedback on her or his performance (Public Service Commission, 2007a, p. 42)

An effective performance review and assessment system should be based on clear ethical principles of trust, openness, fairness and a focus on individual development. During these reviews a mutual agreement should be reached of what the individual performance strengths and weaknesses of staff and the SMS are. Based on the identified weaknesses, appropriate management training and development would be an effective and key intervention to improve the quality of the SMS (Van der Waldt, 2005, p. 53; Blanchard, 2004a, p. 46). According to the Public Service Regulations (2001, p. 78) the SMS should have ongoing and equitable access to training (step four), geared towards achieving an effective public service, through increased work performance and career development. The Presidential Review Commission (1998, p. 33) also recommended that the SMS should receive more coaching and mentoring to improve management practices and to achieve better results against agreed goals. It should become increasingly driven by individual and team needs and link strategically to broader human resource management practices and programmes. The South African Qualifications Authority Act, 1995 (Act 58 of 1995) Section 1 prescribes that occupational training should be outcome based and be aligned to registered and appropriate Unit Standards and Qualifications (Acts, 1995, online).

The South African Cabinet in November 2006 approved the establishment of a Public Sector Academy (PSA) involving a new strategy and organisation, to replace the current SAMDI (SAMDI, 2007, p. 4-5). The PSA, with key partners such as universities who have been contracted by the PSA in various provinces, would play a major role in the development of the SMS. On August 1 2008, the SAMDI/PSA was launched as the Public Administration and Management Academy (PALAMA).

\section{Problem Statement}

The key management practices that are applied in the DoL and the SETAS do not comply sufficiently with the required standards. Non-compliance against the standards affects the extent to which the CG principles of effectiveness, accountability, fairness and transparency are achieved. In addition the non-compliance of applied management practices against the prescribed standards, affects the ability of the SMS to convert policy into practice (DPSA, 2000, p. 3, Bovaird \& Loffler, 2004, p. 132), which is currently not the case.

\subsection{Aim and objectives}

The primary aim was to identify the key weaknesses of the management practices within the DoL and the SETAS and to draft guidelines how the practices could be improved. The secondary objectives (related to the management practices that are executed during the PM\&D cycle) are to:

Identify the required standards for management practices;

benchmark the applied management practices against the prescribed standards of management practices; and 
recommend improvements in the DoL and SETAS which can also be applied to the rest of the government.

\section{Research Method}

The required standards for management practices was determined through a literature study of applicable legislation, regulations, policies, journals, books and newspapers. The applied management practices in the DoL and SETAS was thene benchmarked against the required standards to identify areas of non-compliance.

These practices had been determined through a qualitative study of internal management documents, newspapers, reports, journals and interviews with the SMS and staff. Based on the findings, recommendations was formulated how the applied management practices could be improved.

The four phases of the PM\&D management cycle are used as a research framework for management practices. However, the four phases were not researched in isolation, as effective integration of the phases is indeed a critical and prescribed management practice.

\section{Findings and Guidelines}

The planning phase covers the departmental work plan, the budget and the PA of the DG / HoD and the SMS. The PA specifies the required goals that the SMS take responsibility and accountability to achieve. The nature of the goals should cover two key performance areas, the KRAs (strategic and operational goals) and the GMAs, which should respectively be allocated an importance weight of $80 / 20$. The guidelines would focus on how management practices, relating to the two performance areas, could be improved. As the GMAs are more generic of nature and therefore appropriate to all levels of government and management, more emphasis would be placed on the practices related to the GMAs, than on the KRAs, which would be more departmental specific.

\subsection{Planning phase}

The first guideline to be discussed is how to improve the management practice and compliance during the planning phase. In this regard the KRAs would be discussed as the one part of the WP and the PA. It is suggested that SMART macro strategic goals be drafted which would cover the priority areas of government such as poverty and unemployment alleviation, crime reduction and economic growth (Labour, 2003, p. 1). The drafting of the goals could be coordinated by the Presidency and would include departments such as the DPSA, DPLG and National Treasury. The respective Ministers and / or deputy ministers and DGs or HoDs should also be part of this process. After the goals are drafted, discussed and agreed upon it is allocated to the respective institutions and accounting authorities. These goals are incorporated into the PAs of the HoDs and a higher percentage weight (than other functional or operational goals) are negotiated. In case of the DoL the measurable and specific NSDS goals and indicators are included in the WP and the PA of the DG and the reporting SMS. The PA of the DG therefore become the base from where the NSDS goals are cascaded to the various SETAS. The strategic NSDS goals and the GMAs become the basis of the Service Level Agreements (SLAs) between the SETAS and the Branch: ESDS. The SLAs are the legal document that specifies the goals against which the performance of the SETAS are monitored, assessed and monitored (Labour, 2004, p. 27).

The second performance area to be addressed is the GMAs, which are the generic management outputs and indicators. The GMAs relate to how managers perform in their jobs against agreed management outputs and indicators that are important to most managerial jobs and accountabilities (DPSA, 2003, p. 12). In addition to the KRAs that are part of the PA of the DGs / HoDs, which should be delegated to the reporting SMS, the GMAs should be managed in a similar manner. Four of the GMAs are mandatory namely Information, People, Financial and Client Management. As noted in Rubric Two these outputs should be allocated SMART KPIs and would be applicable to all the SMS at all levels of government. The GMAs will be drafted in a similar manner as the KRAs. Therefore the process should be coordinated by the Presidency and includes departments such as the DPSA, DPLG and National Treasury. Members of the PSC are also involved, as the PSC is mandated to do a qualitative assessment of the PA of DG / HoD and to coordinate the assessment of the DG / HoD (PSC, 2007, p. 36).

An option to allow the SMS to add GMAs, which are activity based, to their PAs is retracted as it undermines accountability (DPSA, 2002, p. 17). These activities are integrated in the PDPs and the training and development (T\&D) programmes but not for performance planning, reporting and assessment. It is replaced with the above example where the GMAs consist of SMART outputs and KPIs, so that areas of non-compliance or weaknesses are easily identified. 
Based on the weaknesses, corrective and development interventions are implemented and some of the actions can include relevant management T\&D.

Additional assessments and the results, such as the liP assessment, are integrated with the appropriate GMA and KPI. For example, the liP assessment forms part of the People Management Output and the indicator 2.3, Satisfactory rating of manager by team members (Based on related Unit Standards and assessment criteria, rated bi-annually). Therefore an integrated evaluation instrument is applied, which is applicable to a specific SMS member and is completed by the team. The instrument incorporates the required standards, the liP indicators and the assessment criteria of the relevant Unit Standards of the National Management Qualification. The instrument has been constructed in such a way that the competence of the SMS member will be evaluated by the team after the completion of the planning, reporting, assessment and T\&D phases. This approach would ensure that assessments, such as the liP evaluation, are not perceived by the SMS as an additional and unimportant assessment because it is not part of the PA.

The principle of a pre-consistency rating is implemented to ensure a more transparent, objective and fair approach to goal setting, monitoring and reporting and assessment. The principle is more appropriate to the GMAs that are generic, versus the KPAs that are department specific. The pre-consistency rating should be done during the goal setting phase and entails the identification and agreement of what the required levels of performance results are for each of the five point rating scale (City of Cape Town, 2008, p. 8).

Based on the suggested pre-consistency ratings an adverse, disclaimer and qualified opinions are viewed as an unacceptable performance rating and are rated as such. An emphasis of matter opinion is viewed as an acceptable rating (considering the past and current baselines) and an unqualified opinion as an exceptional rating. A four rating is applicable to a department that retained its unqualified opinion of the previous year and a five rating is applicable to a department that has improved from a lower opinion level the previous year, to an unqualified opinion in the current year. Additional procedures are applied to the various ratings to ensure that the potential leverage of the PM is maximised. For example, if the department receives an adverse or disclaimer opinion, the SMS is allowed any performance bonuses, irrespective of performance results in other areas. The same procedure is applied if the department receives a qualified opinion in two and more consecutive years. The leverage of the PM system will not be maximized if the SMS receive performance bonuses whilst a department receives a disclaimer, adverse or qualified opinion, which indicates a serious non-compliance against the financial regulatory standards (City of Cape Town, 2008, p. 10).

\subsection{Monitoring and reporting phase}

Monitoring of a programme performance is based on the standard of performance against pre-set outputs and KPIs. In practical terms, monitoring involve the routine collection of data on all the KPIs in relation to the strategic and performance plans, the preparation of reports on different levels by comparing the KPIs against actual results (Schienle, 2007, p. 151). Different monitoring frameworks may be designed depending on the intended focus of the monitoring (PSC, 2008b, p. 48). Monitoring from a financial management perspective, for example, may include monitoring of expenditure against budget or monitoring whether financial prescripts and controls are adhered to. Frameworks, rules and conventions for financial monitoring are established in the Public Service through legislation such as the PFMA. Despite this, shortcomings in the financial monitoring remain a main reason for qualified audit outcomes (Schienle, 2007, p. 156).

The most common deficiencies which were reported in the management letters to the relevant auditees were: non-compliance with the requirements of the PFMA to report on performance against predetermined goals;

goals were reported on in the annual report, while these goals have not been pre-determined in the strategic plan;

- goals reported on in the annual report were materially different from the pre-determined goals specified in the strategic plan; and

- the reported performance information was materially inconsistent in comparison to the evidence gathered during the evaluation (AG, 2007, p. 24).

To improve these deficiencies and other areas of non-compliance, an additional guideline is to incorporate the following monitoring and reporting procedures in a national PM policy that will be applicable to all public organisations. The procedures will instruct that monitoring and reporting will be

based on the agreed Work Plans and aligned PA of the HoD (agreed outputs and indicators);

concise and specific (use numbers, percentages, rands, dates and state if achieved or not achieved);

timely (delivered on time, according to the agreed dates of a national planner); and 
accurate (the results are based on reliable sources, and can be verified. (City of Cape Town, 2008, p. 21)

Ellig $(2007$, p. 4) has listed three key standards that public reports should comply with namely transparency, public benefits and forward looking leadership. Transparency can be improved by publishing short versions of Annual Reports by making applying visual aids that would be understandable for semi-literate citizens. In addition, the copies of these versions should be available at the community centers that are visited frequently by rural citizens. Public benefits should clearly be illustrated by listing the agreed outputs, outcomes and KPIs against the results achieved. The goals and results should be clear, specific and measurable and should indicate the cost and if applicable, the cost per unit. This would allow citizens to determine the degree of success that government has achieved and the cost at which it has been done. Forward looking leadership will be in the form of a short synopsis where the SMS indicate, based on the agreed goals versus results and costs, how they intend to improve and / or review the appropriate programmes and policies (City of Cape Town, 2008, p. 13). The organisational and managerial achievements and weaknesses that were identified during this phase should determine the assessment rating of the SMS that is addressed in the following phase.

\subsection{Review and assessment reporting phase}

Progress against performance objectives and goals and competency gaps should be reviewed more in terms of the organisational vision, mission and strategy rather than functional responsibilities and duties (Miller, 2005, p. 112). In this regard audit reports provide valuable inputs that can be applied by the SMS to review the organisational weaknesses. The General Report 2006/7 of the AG (2006, p. 19) indicated that nine national departments have consistently received qualified audit opinions for the last three to five years. Most of the problems that were linked to the qualified audit opinions were basic internal control compliance issues that require the effective monitoring and review by the SMS so that it is addressed immediately (AG, 2006, p. 19).

In addition the SMS should address structural internal control processes that seems to be confined nationally to capital asset management. All the departments that were qualified had problems to accurately account for capital assets. The AG $(2006$, p. 20) recommended that with the assistance of the National Treasury, the departments should implement a structural plan with clear milestones and to report against those milestones to address the identified weaknesses in the management and accounting for capital assets. The ability of departments and the SMS to identify, monitor, review and correct errors in a timely manner is a key consideration. The initiatives should be monitored and reviewed on a periodic basis by the DG / HoD and the legislature (AG, 2006, p. 19). Turnaround strategies which have been implemented by other government agencies, in consultation with the National Treasury, resulted in a drastic reduction in the number of qualifications.

Cabinet adopted a framework for the evaluation of the HoDs in 2000, and in 2002 a decision was taken to make compliance with the evaluation framework mandatory for all National and Provincial departments (PSC, 2008b, p. 4). In order to facilitate the evaluation of the HoDs, the PSC issues guidelines on an annual basis. The guidelines require the Executive Authorities (EAs) to appoint evaluation panels to assist the EAs with the assessment of the HoDs. The nomination of members to serve on evaluation panels is at the discretion of the EA. The evaluation panels can reflect all stakeholders as dictated by the nature of the department concerned and may also involve the peers of HoDs. In addition to the Chairperson from the PSC, the number of panel members should be between three to four members. The panels should be constituted as follows:

A Minister from the same Cabinet cluster in the case of national HoDs, and a MEC in the case of provincial HoDs;

one peer of the $\mathrm{HoD}$; and

one or two persons representing key client(s) or stakeholder(s) of the department (PSC, 2008b, p. 6).

The role of the evaluation panels is to advise the EA on the performance of the HoD. The members of the panel must be objective and must strive to formulate advice based on facts and not assumption (PSC, 2008b, p. 6). In addition to the PSC guidelines and to further increase the objectivity of the evaluation and rating of the HoD, the pre-consistency principle can be applied to the GMAs, as discussed earlier in this rubric, by the evaluation panels. Due to the large number of departments that received qualified audit opinions it would also be useful to appoint a member of the office of the AG to the panel to ensure that Financial Management is treated as a priority during the assessment phase. Furthermore, the panel should ensure that an assessment rating of the organisation and the DG is done simultaneously and that the rating of the DG informs the rest of the assessment ratings of the SMS. To extend the objectivity and consistency of the assessment ratings beyond the DG to the rest of the organisation, a national policy should be approved that states that the average assessment ratings of the SMS will not vary more than $5 \%$ of the rating of the DG. 
Higher variances will be allowed at lower levels of the organisation as staff on lower levels cannot make the same impact on the organisational effectiveness as the SMS (Labour, 2004, p. 14).

\subsection{Training and development phase}

The training and development (T\&D) phase is based on the results of the performance assessments, which are based on the reports and the relevant and aligned WPs and PAs. The GMA framework should be developed into a matrix of foundational competencies and proficiency levels for the SMS, mapped to the salary levels, which would provide a more authoritative and standardised guidance for the SMS, than is currently the case (City of Cape Town, 2008, p. 11). An objective assessment of the proficiency in the appropriate GMA should be a pre-requisite, amongst other criteria, for the progression of the SMS through the salary levels. This approach should be applied during the performance assessment of the SMS, as is currently required, but the weighting of the GMAs should be increased to $25 \%$ (from $20 \%$ ) of the overall performance evaluation weighting (City of Cape Town, 2008, p. 12). The mobility of the SMS suggest that a portable competence passport, reflecting technical and professional proficiencies acquired, but especially in relation to the GMAs, is necessary to be lodged with the SAQA and updated annually by the PALAMA and PSETA and be based on accredited assessment results (City of Cape Town, 2008, p. 12).

The SMS should be base-lined for development through a scientific skills assessment process to identify the required training needs and skills gap (Mullins, 2002, p. 44). Such a process would include two integrated assessment processes. The first assessment will be an assessment of the degree of compliance by the department and the operational function that the SMS is responsible for, against the KPAs and as a minimum, the four mandatory GMAs. This assessment should be done in collaboration with institutions such as the AG, PSC and the DPSA. To ensure improved objectivity and consistency across departments, provinces and local governments, the pre-consistency rating principle should be applied to the GMAs (Media Advertising Packaging Printing and Publishing SETA, 2007, p. 26).

The second assessment (informed by the results of the first assessment) will be of the competence and proficiency levels of the SMS against the four mandatory GMAs, as a minimum (if not for all the GMAs). The assessments should be conducted by independent Public Sector Management experts, who are registered as assessors with the PSETA against an appropriate Public Management Qualification (City of Cape Town, 2008, p. 17). Linking the GMAs development programme to a vocational qualification would present certain challenges and advantages. During the RPL of the SMS, accredited assessment instruments will be applied by the registered assessors (City of Cape Town, 2008, p. 19). The key advantages of applying the assessment criteria and instruments of a vocational qualification and a RPL process are two-fold. Firstly, a large number of the assessment instruments could be based on work related examples and evidence that are part of the job requirements. For instance, completed, agreed and timely submitted PAs (that meet the SMART criteria and are aligned to the strategic goals) monthly, quarterly and annual reports and the MTEF budgets are required standards and documents.

These documents are compiled in a Portfolio of Evidence and are submitted for assessment and moderation. Such assignments are less theoretical of nature as it is more aligned to the job and work requirements of the SMS. As the assignments are directly linked to the job requirements it will also be perceived by the SMS as a learning orientated process, the preferred orientation of learners, rather than a grade orientated process (Van Staden, 2006, p. 10-12). Secondly, the unit standards and assessment criteria are of a generic nature and are applied specifically to the required work environment. If significant gaps are identified in more than one mandatory GMA, it will be regarded as a skills deficit that needs to be addressed in a single performance cycle. It implies that the manager is not able to perform from a fundamental perspective, and extraordinary efforts and commitment are required by the SMS to eliminate the deficit (SAMDI, 2007, p. 9).

Another mandatory GMA client orientation was also a matter of concern. Given the often poor ratings due to inadequate public service delivery, the client orientation focus was a GMA that deserves more attention by the SMS. This issue has been recognised by the DPSA when it declared client orientation a mandatory GMA for the SMS (City of Cape Town, 2008, p. 11). However, a careful analysis of the key causes of poor service delivery / client orientation needs to be executed, before training and development are applied as the desirable instrument to solve the problem. This principle is not only applicable to client orientation, but should be universally applied to any organisational and / or individual weakness.

However, if the key cause of non-compliance and / or poor performance is due to incompetence, the PALAMA will be required to devise ways of addressing the skills gaps with appropriate T\&D modules for the SMS. The GMA development gap ranking offers a certain prioritisation for the developing and rolling out of a formal and accredited GMA 
development programme (Schienle, 2007, p. 51). Accreditation implies that the training programme is linked to a qualification and the related unit standards.

The curriculum will require the SMS to collect the required evidence of competence that is aligned to regulatory standards and the unit standards and compile and submit it for assessment and moderation in order to be accredited when declared competent. The curriculum also offers an RPL option which should, as indicated earlier in this rubric, be linked to the organisational performance results based on the KPAs and GMAs. The impact of the T\&D interventions could also be measured by comparing the performance results before and after the training. For example, if the department received a qualified audit report it is the responsibility of the SMS to determine the key causes and to rectify the areas of non-compliance. One option of corrective action could be training and development and the results of the following audit report will indicate how successful the training and development was (City of Cape Town, 2008, p. 44).

The T\&D interventions should not be limited to traditional classroom lectures and assignments, which are more generic, but should include work specific interventions through mediums such as on-the-job training, RPL, mentoring, coaching, shadowing, job rotation and self study (Miller \& Robins, 2007, p. 88). A T\&D impact or outcome measurement can be an increase or decrease of compliance against the relevant KRA or GMA, which should be evident in the following performance report. If the T\&D are integrated effectively with the three phases of the PM\&D cycle the SMS will become more serious about development, as it will be linked to PAs, performance reports, assessment ratings and performance bonuses (Labour, 2004, p. 78).

\section{Concluding Remarks}

An effective public sector is a crucial role-player to ensure that the development of all sectors of a country is efficient and sustainable. This is especially true for a developing country such as South Africa that needs to address macro socioeconomic challenges such as poverty and unemployment. The SMS in the public sector have a pivotal role to ensure that the public sector is managed effectively. The quality of public service delivery and the degree of compliance against CG principles are key indications of how effective the SMS are managing the public sector.

The SMS should therefore be held accountable to deliver a public service that is effective, fair, transparent and coherent. This type of public service requires management practices to comply with Constitutional and CG principles. The key operational management practices are mainly executed during the four phases of the Performance Management and Development (PM\&D) cycle, namely planning, monitoring and reporting, review and assessment and T\&D of the SMS.

The guidelines proposed, based on the identified weaknesses should improve the degree of compliance of the management practices. The improvement in compliance should ensure a more effective public sector, which delivers a better service to all citizens and contribute effectively to the sustainable socio-economic growth and development in South Africa.

\section{References}

Adam, M. (2005). Creating Sustainability through Good Governance. Sunday Times, May 8, p.5.

Blanchard, K. (2004a). The One-minute manager builds high performing teams, increase satisfaction and productivity to achieve excellence. London: Harper Collins Publishers.

Blanchard, K. (2004b). The One-minute manager increase productivity, profits and your own prosperity. London: Harper Collins Publishers.

Bovaird, T. \& Loffler, E. (2004). Public Management and governance. London: Routledge Publishers.

City of Cape Town. (2008). The Resort Project: Business Planning. Cape Town.

Ellig, J. (2007). Scoring Government Performance Reports. The Public Manager, 36, (2).

Gordan, G. (2007). Effective Public management. Business Times, September 12, pp.5, 21.

King, M. (2002). King Report on Corporate Governance. Parklands: Institute of Directors.

Miller, G.J., Robins, D. (2007). Incentives, Certification, and targets in Performance Budgeting. Public Performance \& Management Review. New York: M.E. Sharpe Incorporated.

Mullins, L.J. (2002). Management and Organisational Behaviour. New York: Prentice Hill.

Online Dictionary. (2013). Management practices. [Online]. Available from: www.dictionary.com Date Accessed July 30, 2013).

Presidential Review Commission. (1998). Developing a culture of good governance, a report on the reform and transformation of the public service in South Africa. [Online]. Available from: www.gov.za/reports/prc98/part/htm Date accessed October 22, 2005.

Republic of South Africa. The South African Qualifications Authority Act, (Act 58 of 1995). Pretoria: Government Printer.

Republic of South Africa. The Constitution of the Republic of South Africa, (Act 108 of 1996). [Online]. Available from: 
http://www.acts.co.za/constitution/index.htm Date accessed March 22, 2013.

Republic of South Africa. Department of Public Service and Administration. (2000). Report on the study on the senior layer of the public sector. Pretoria: Government Printer.

Republic of South Africa. Department of Public Service and Administration. (2001). Public Service Regulations. Pretoria: Government Printer.

Republic of South Africa. Department of Public Service and Administration. (2002). Performance Management Policy for Senior Management Staff. Pretoria: Government Printer.

Republic of South Africa. Department of Labour. (2003). Growth and Development Summit. Pretoria: Government Printer.

Republic of South Africa. Department of Labour. (2004). Report: The transformation of Employment and Skills Development services. Pretoria: Departmental Printing.

Republic of South Africa. Department of Labour. (2005). The National Skills Development Strategy 2005-2010. Pretoria: Government Printer.

Republic of South Africa. Department of Labour. (2006). The Annual Report 2005-2006. Pretoria: Government Printer.

Republic of South Africa. Public Service Commission. (2006). Report to the Presidency on the implementation of the Framework for the Evaluation of Heads of Departments. Pretoria: Government Printer.

Republic of South Africa. Auditor-General. (2007). Audit Outcomes of National and Provincial Departments for the financial year 200607. Pretoria: Government Printer.

Republic of South Africa. Public Service Commission. (2007). Report on the State of the Public Sector. Pretoria: Government Printer.

Republic of South Africa. Public Service Commission. (2008a). Report on the Evaluation of the Training Needs of the Senior Management Staff in the Public Sector. Pretoria: Government Printer.

Republic of South Africa. Public Service Commission. (2008b). Basic concepts in monitoring and evaluation. Pretoria: Government Printer.

Schienle, K. (2007). Best Practices: Achieving Goals. New York. Harper Collins.

South African Management Development Institute. (2007). Strategic Plan 2008/9 - 2010/11. Pretoria: Government Printer.

Van der Waldt, G. (2005). Managing performance in the Public Sector. Landsdowne: Juta and Co.

Van Staden. E.L. (2006). Entrepreneurialism and innovation within a University of Technology - Contribution to Higher Education Institutions. In: $4^{\text {th }}$ International Conference on Entrepreneurship and Innovation. Pretoria: Tswane University of Technology. 
